\title{
Modals in Arab EFL Learners' Composition: A Corpus-based Approach
}

\author{
Mousa A. Btoosh \\ College of Sciences and Humanities, Fahad Bin Sultan University, Saudi Arabia
}

Copyright $\subseteq 2019$ by authors, all rights reserved. Authors agree that this article remains permanently open access under the terms of the Creative Commons Attribution License 4.0 International License

\begin{abstract}
This study presents a corpus-based investigation of how Arab students of English use modality in academic writing. Although the primary focus of the study is on the writing of Arab L2 learners, regular comparisons have been conducted with native-speakers' writing with the aim of delineating the areas of similarities and differences between the two groups (leaners and native speakers). Furthermore, in an attempt to check whether the features characterizing the use of modality in Arab L2 academic writing is part of a general tendency or an idiosyncratic creation that exclusively applies to Arab students of English, results have been frequently checked against some other relevant studies. The study reveals a gap between native speakers and learners in terms of the frequency count of the modals used. Findings also show that many of the modality features used in the learner corpus reflect a general tendency on the part of most L2 learners. Yet, some other features, including the overuse of 'must', 'can' and 'should' and the underuse of the epistemic modals 'may', 'might', 'would', and 'could', are likely to be attributed to both learners' general tendency and L1 rhetoric, where certainty-oriented and collectivistic-oriented styles prevail.
\end{abstract}

Keywords Modals, Verbs, Arab, Corpus, Learners

\section{Introduction and Review of Literature}

Modality is an umbrella term that covers numerous natural language expressions, viz., modal auxiliary verbs (e.g. will, shall, may), lexical verbs (e.g. wish, think, believe), adverbs (e.g. possibly, perhaps, clearly), phrasal modals (e.g. ought to, have to), nouns (e.g. possibility, probability, certainty), and adjectives (e.g. possible, probable, certain). In fact, modality does not lend itself to an easy definition perhaps because it means many things to many people. Semantically speaking, modality refers to the expressions conveying a speaker's attitude to what an utterance denotes. Huddleston (2002: 173) illustrates that modality is "centrally concerned with the speaker's attitude towards the factuality or actualization of the situation expressed by the rest of the clause." Thus, according to Huddleston, unmodalised and modalised clauses express divergent factuality degrees of the same proposition, as shown in (1).

(1) a. He wrote it himself. b. He must have written it himself.

The speaker in (1a) is committed, without qualification or special emphasis, to the factuality of the proposition expressed. However, in the modalised (1b) although "I still commit myself to the factuality of his having written it himself, my commitment is qualified in the sense that the truth of the proposition is not presented as something that is directly known but as something that is inferred." (ibid.). So, it seems true that the importance of modality stems from its ability to convey the sender's attitude to both the proposition and the receiver. A look at literature shows that the concern with modality has dramatically changed over time.

The linguistic research on modality has gradually shifted since the second half of the past century from a monolithic, static conception to a more dynamic understanding of modality. That is, greater attention has begun to be given to the relevance of linguistic and extralinguistic contextual factors in the production and interpretation of modal utterances in discourse (Bybee \& Fleischman, 1995). In principle, natural language modals are generally specified for modal force (possibility and necessity) and modal flavours (epistemic modality, dynamic modality, and deontic modality) (Palmer, 1990: 6-7).

Epistemic modality is essentially speaker-oriented as it makes a judgment about the truth of the proposition. In other words, epistemic modality is primarily concerned with the sender's judgment, belief, or opinion about the factual status of the proposition since the speaker does not have full knowledge of the situation or what actually happened. According to Lyon (1977: 52), epistemic 
modality refers to "the speaker's opinion or attitude toward a proposition that a sentence expresses or the situation that the proposition describes." In other words, this category refers to the way speakers communicate their doubts or uncertainties as they do not have full knowledge of a situation. For Hoye (1997: 42) epistemic modality is concerned with matters of knowledge or belief, which form the basis of speaker's judgment about state of affairs, actions or events in terms of possibility or necessity. Based on Mitchell (2009: 66), epistemic modal utterances express a speculative or verdictive function.

(2) a. She must be sick. (logical conclusion)

b. She may be sick. (possibility)

Dynamic modality, on the other hand, is concerned with the ability and volition of the subject of the sentence. Accordingly, dynamic modality is subject-oriented as it is solely devoted to the subject's ability or willingness. Nuyts (2006) distinguishes between two types of dynamic modality, namely, dynamic ability and dynamic necessity. Kehayov (2017) argues that ability and internal need can be either physical or emotional, as shown in (3).

(3) a. He can lift a Tarabant with one hand. (dynamic possibility: physical)

b. He can tell you the capitals of all African countries. (dynamic possibility: mental

c. I need to have a nap, I'm so tired. (dynamic necessity: physical)

d. I need to call her, I miss her so much. (dynamic necessity: emotional)

Unlike epistemic and dynamic modality, deontic modality is concerned with the use of language to express desires, wants, commands, obligations, undertakings, and permission. Deontic modality can be divided into four subcategories, viz., directives (deontic possibility: you may leave; deontic necessity: you must leave), commissives (promises, undertakings: you shall be rewarded), imperatives, and volitives and evaluatives (Stefanescu,
2007). As they place obligations or commands on the part of the addressee, deontic modals are considered addressee-oriented. Irrespective of the sharp contrast between the categories of modality, it still remains hard to draw clear-cut boundaries between them based on the modals used as some modal auxiliaries are specified for one kind of interpretation while some others express divergent modal flavors (e.g. 'may' and 'must'). The following instances exemplify the multiplicity of modal meanings.

(4) a. Tom may leave tomorrow.

b. Mary can drive her car.

'May' in (4a) can be interpreted as permission or possibility. That is, Tom has the permission to leave tomorrow, or it is possible that he leaves tomorrow. In the second example (4b), it is either that Mary is able to drive her car, or she has the permission to drive her car. The point here is that despite the different modal verbs in (4a) and (4b), they are still both used to express permission. Modality, as the literature shows, is not language specific. Rather, it is a universal semantic category that is used in almost all world languages, including Arabic.

Drawing on El-Hassan (1990: 164), Arabic is capable of expressing a wide range of epistemic and deontic modes of modality:

Arabic is shown to be capable of expressing a wide range of epistemic and deontic modes of modality in its own terms, i.e. independently. In other words, modality in Arabic can be studied without reference to English, or any other language for that matter. What is important to establish here is whether modality in Arabic is a lexical or grammatical category.

Providing an integrative analysis of Arabic modality expressions, Es-Saaydeh (1996: 46) clarifies that Arabic modality is rather a lexical category. Through the following chart, Es-Saaydeh summarizes the basic English modals and their counterparts in Arabic. 
Table 1. Summary of the English modals and Arabic modality expressions

\begin{tabular}{|c|c|c|c|}
\hline $\begin{array}{l}\text { Kind of } \\
\text { Modality }\end{array}$ & Modalities & English Modals & $\begin{array}{ll}\text { Arabic } & \text { Modality } \\
\text { Expression } & \end{array}$ \\
\hline \multirow[t]{5}{*}{$\begin{array}{l}\text { Epistemic } \\
\text { Modality }\end{array}$} & $\begin{array}{l}\text { Possibility: } \\
\text { Speculation } 1\end{array}$ & may/might & $\begin{array}{l}\text { yumkin, rubbama, la9alla, } \\
\text { gad, yuhtamal }\end{array}$ \\
\hline & Speculation 2 & should / ought to & ?adunnu, 9alal ?arjah \\
\hline & Confidence & will & $\begin{array}{l}\text { ?a9taqid, 9ala yaqiin, bitta? } \\
\text { kiid, minalmuk?kkad,? } \\
\text { akiid }\end{array}$ \\
\hline & & must & laabudda \\
\hline & & can't & laa budda ... laa / laysa \\
\hline \multirow{8}{*}{$\begin{array}{l}\text { Deontic } \\
\text { Modality }\end{array}$} & Deontic Possibility & & \\
\hline & Permission & may & yumkin laka \\
\hline & & can & yumkin \\
\hline & Deontic Necessity: & & \\
\hline & Obligation & must & yajib \\
\hline & Undertaking & $\begin{array}{l}\text { shall (promise and threat) } \\
\text { shall not(promise and threat) } \\
\text { shall (obligation) } \\
\text { shall (determination) } \\
\text { shall (regulation) }\end{array}$ & $\begin{array}{l}\text { la (sawfa) } \mathrm{vb}+\text { nunnation } \\
\text { lan } \\
\text { stressed } \mathrm{sa}^{\wedge} \mathrm{vb} \\
\text { mușir } \\
\text { 9ala }\end{array}$ \\
\hline & Hope & may & la9alla, 9asa \\
\hline & Desire & would & layta \\
\hline \multirow[t]{7}{*}{$\begin{array}{l}\text { Dynamic } \\
\text { Modality }\end{array}$} & $\begin{array}{l}\text { Dynamic } \\
\text { possibility: } \\
\text { Neutral possibility }\end{array}$ & can, could, may & yumkin \\
\hline & $\begin{array}{l}\text { Subject-oriented } \\
\text { possibility }\end{array}$ & can, be able to & $\begin{array}{l}\text { ?astaTii9 ..., ?amkana, } \\
\text { bimaqduuri }\end{array}$ \\
\hline & $\begin{array}{l}\text { Subject-oriented } \\
\text { Modality: } \\
\text { Willingness } \\
\text { Habit } \\
\text { power }\end{array}$ & $\begin{array}{l}\text { will, be willing } \\
\text { will, would / could } \\
\text { will }\end{array}$ & $\begin{array}{l}\text { ?uriid, 9alas sti9daad } \\
\text { mu9taad, ... } \\
\text { yastsTii9 }\end{array}$ \\
\hline & $\begin{array}{l}\text { Dynamic necessary: } \\
\text { Neutral necessity }\end{array}$ & $\begin{array}{l}\text { must, have to } \\
\text { should, ought to }\end{array}$ & $\begin{array}{l}\text { yajib } \\
\text { yanba9ii }\end{array}$ \\
\hline & External necessity & have to & mudTar, etc. \\
\hline & Internal necessity & need & yanbai, daa $\underline{9} \mathrm{i}$ \\
\hline & & need have & kaana yanga $2 \mathrm{i}$ \\
\hline
\end{tabular}

\subsection{Learners Interlanguage}

The twentieth century witnessed the evolvement of numerous linguistic approaches and frameworks that have been used in the analysis of language data. This century also brought us the dawn of the digital information age. The rapid advancement in technology and the increasing concern with language acquisition and analysis during the past seven decades have given rise to corpus linguistics. The growing recognition given to corpus linguistics is essentially attributed to its ability to provide natural language data and to go beyond clause level to include the discourse or textual unit.

A well-built and representative corpus provides an ideal platform for researchers to access numerous features and data that would be otherwise hard to obtain (Kennedy,
1990; Biber et al., 1998, to name just two). These include:

(i) the different contextual meanings associated with a particular word;

(ii) the commonly found words that co-occur with a particular word (collocations);

(iii) the frequently used vocabulary in a language or a domain; and

(iv) the non-linguistic association patterns that a particular word has to a register or a dialect.

The data provided by a corpus are naturally occurring, and thus, they are believed to be superior to any non-natural or hypothetical data. From this perspective, Kennedy (1998: 7-8) asserts that corpus linguistics is not a theory in competition with other linguistic theories. Rather, it is a source of evidence that comprises the core of any 
linguistic study. For Aijmer \& Altenberg (1991: 2), corpora have become excellent resources for a wide range of tasks. This, they argue, is due to two main reasons:

a. Language corpora have provided a more realistic foundation for the study of language than earlier types of material, a fact which has given new impetus to descriptive studies of English lexis, syntax, discourse and prosody.

b. Language corpora have become a particularly fruitful basis for comparing different varieties of English, and for exploring the quantitative and probabilistic aspects of the language.

Thus, this corpus-based study seeks to explore the use of modals in the academic writing of Arab students of English. To achieve this purpose, both quantitative and qualitative analyses have been conducted.

\section{Methodology}

In response to the study objectives listed above, this study employs a corpus-based approach to address three research questions.

A. Are there any disparities between Arab EFL learners and native speakers in terms of the number of the used modals?

B. Are there any similarities or differences between Arab EFL learners and other EFL learners in terms of the used and use of modals?

C. What are the reasons that make Arab EFL learners' use of modal verbs different from that of native speakers?

For the purpose of this study, two corpora representing learners and native speakers' academic writing have been used. The learner corpus comes from the Interlanguage Corpus of Arab Students of English (ICASE, hereafter), which was compiled by the researcher. The corpus consists of 100, 229 tokens. In the course of data collection, 609 Jordanian undergraduate students enrolled in their second to fourth year of English Language and Literature at five Jordanian universities volunteered to participate in this study. The native tongue of all the subjects, who, at the time, were considered to be at the intermediate to advanced level of English proficiency, is Arabic. It is worth to mention that there are two versions of ICASE, a raw corpus and an annotated one. The annotated corpus was tagged by CLAWS part-of-speech tagger developed by Lancaster University.

For comparison purposes, an equal-sized native corpus consisting of 100, 549 tokens was employed. This corpus comes from the Louvain Corpus of Native English Essays (LOCNESS), a corpus of argumentative essays written by American and British university students.
In order to address the study objectives, both quantitative and qualitative methods have been used to examine the core modals (can, could, may, might, will, would, shall, should, and must), epistemic modals (may, might, possible, likely, unlikely, sure, probably, certain, and possible), marginal modals (need to, dare, to, and used to), and semi-modals ((had) better, have to, (have) got to, be supposed to, should, and be going to).

By so doing and in addition to providing the frequency count of all the forms of the target modals (e.g. can, cannot, can't, can't), special attention has been given to examine the semantic function and contextual use of these modals in the learner corpus.

\section{Results and Discussion}

According to Carter \& McCarthy (2006: 638), core modals refer to a set of nine modal auxiliary verbs, viz., can, could, may, might, will, would, shall, should, and must. Table (2) presents the frequency count of these modals in both corpora.

Table 2. Frequency count of core modals in learner and native corpora.

\begin{tabular}{|l|c|c|}
\hline \multicolumn{1}{|c|}{ Modal } & Learner Corpus & Native Corpus \\
\hline $\begin{array}{l}\text { can (cannot, can not, } \\
\text { can't) }\end{array}$ & 394 & 281 \\
\hline $\begin{array}{l}\text { could (could not, } \\
\text { couldn't) }\end{array}$ & 53 & 172 \\
\hline may (may not) & 83 & 117 \\
\hline might (might not) & 12 & 26 \\
\hline will (will not, won't) & 291 & 402 \\
\hline $\begin{array}{l}\text { would (would not, } \\
\text { wouldn't) }\end{array}$ & 161 & 410 \\
\hline shall (shall not, shan't) & 200 & 155 \\
\hline $\begin{array}{l}\text { should (should not, } \\
\text { shouldn't) }\end{array}$ & 291 & 109 \\
\hline $\begin{array}{l}\text { must (must not, } \\
\text { mustn't) }\end{array}$ & $\mathbf{1 4 8 7}$ & $\mathbf{1 6 7 3}$ \\
\hline Total & & 15 \\
\hline
\end{tabular}

The figures above present an over 10\% gap between the two corpora in terms of the used modal verbs. The learner corpus has a mean count of around 15 modals per a 1,000 tokens. The native corpus, on contrast, uses around 17 modals per a 1,000 tokens. Yet, these close means should not conceal the substantial gap between the two in terms of the overuse and underuse of some of the given modals. As shown in Table (2), can, will, would, should and must are the most frequent modals in the learner corpus, accounting for $89.9 \%$ of the entire set of the core modals. However, the same modals contribute to only $74.68 \%$ of the entire set of modals in the native corpus. Yet, compared to the native corpus, learner corpus displays just three overused modals, namely, must, should and can. Figure (1) presents the percentage of the modal verbs in both corpora. 


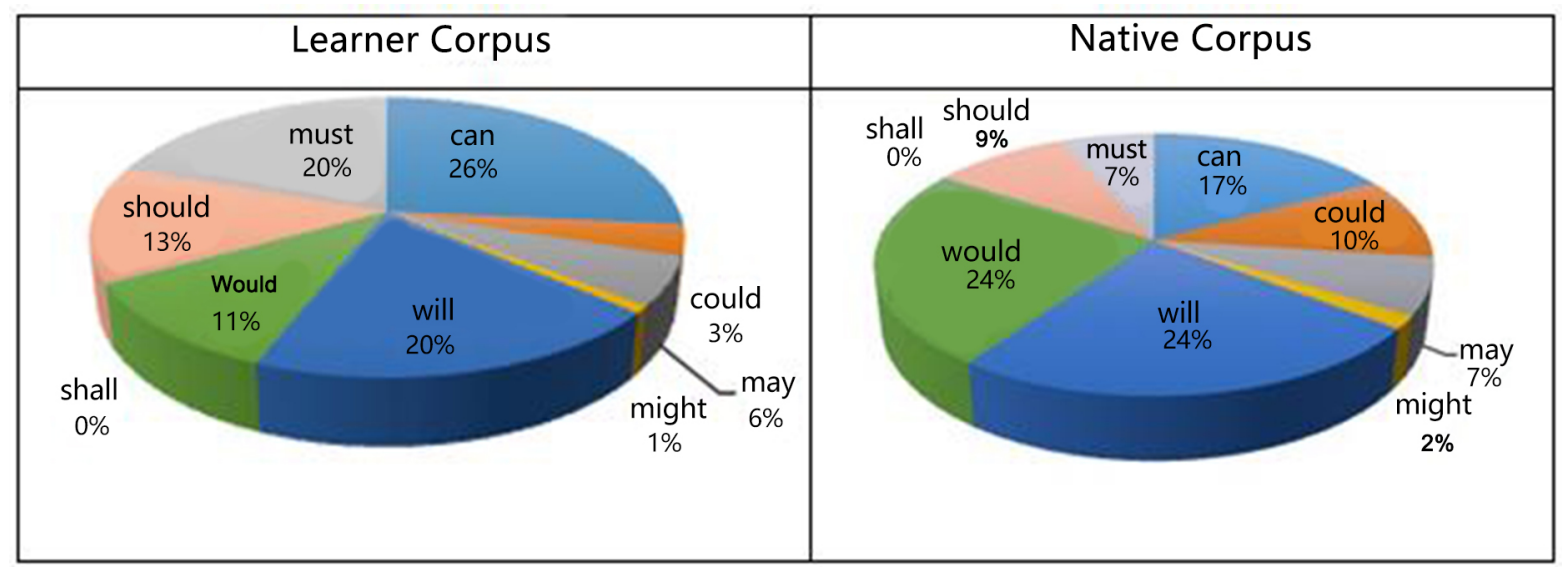

Figure 1. Percentage of epistemic modality in learner and native corpora.

'Must', as discussed earlier, has two basic meanings. The deontic meaning of 'must' implies necessity and obligation while its epistemic meaning is concerned with making confident inferences (Downing \& Locke, 1992; Depraetere \& Reed, 2006; Mortelmans, 2010). Still, 'must' could be (but rarely) used to express a dynamic meaning based on the context of use in which it appears.

The relative frequencies of the modals in Table (2) show that learners have used around thrice as many 'musts' as native speakers did. The overuse of 'must' in learner corpus could be linked to L1 rhetoric, where 'must' is primarily used to strengthen the force of the expressed proposition. So, it is easy to notice that 'must' implies a subjective attitude so as to convey the speaker's strong assertion of the proposition.

Linguistically speaking, certainty rather than probability is a highly favored feature in Arabic discourse as learners' L1 culture is certainty-oriented (Ajami, 2016).

The Arab-Islamic culture is also certainty-oriented in the sense that most Arabs and Muslims consider their beliefs to be certainties, i.e. their beliefs could not be subjected to critique, doubt, and replacement. This essential aspect of the Arab-Islamic culture is related to Arabic language itself. (p. 121)
In addition to learners' L1 rhetoric, the findings above regarding the overuse of 'must' are corroborated in the previous literature. Milton \& Hyland (1999) shed light on the doubt and certainty in the performance of native speakers and Chinese leaners of English. The findings of this study indicate that leaners inappropriately overuse directive and authoritative assertions. Also, by examining the non-native/native differences in the actual inventories of adjective intensification in two native corpora and two non-native ones (around a 100,000 words each), Lorenz (1998: 54) ascertains that the most prominent difference between the German learners of English and native speakers lies in the overall intensifier counts. That is, learners use more intensifiers than native speakers.

Prior to delving into the complexity of the contextual meanings of modals, it should be made clear that modals constitute a slippery category whose meanings are not always clear-cut. At first glance, both 'have to' and 'must' are identical as they express obligation. However, 'have to' and 'must' vary with regard to the source of obligation. 'Have to' is usually used when the obligation is external (e.g. You have to see the doctor soon.) whereas the obligation in 'must' is internal (from the speaker). A close look at the corpus, in general, and the concordance lines in Figure (2) below, in particular, shows that 'must' expresses a variety of meanings, ranging from the deontic to the epistemic. 


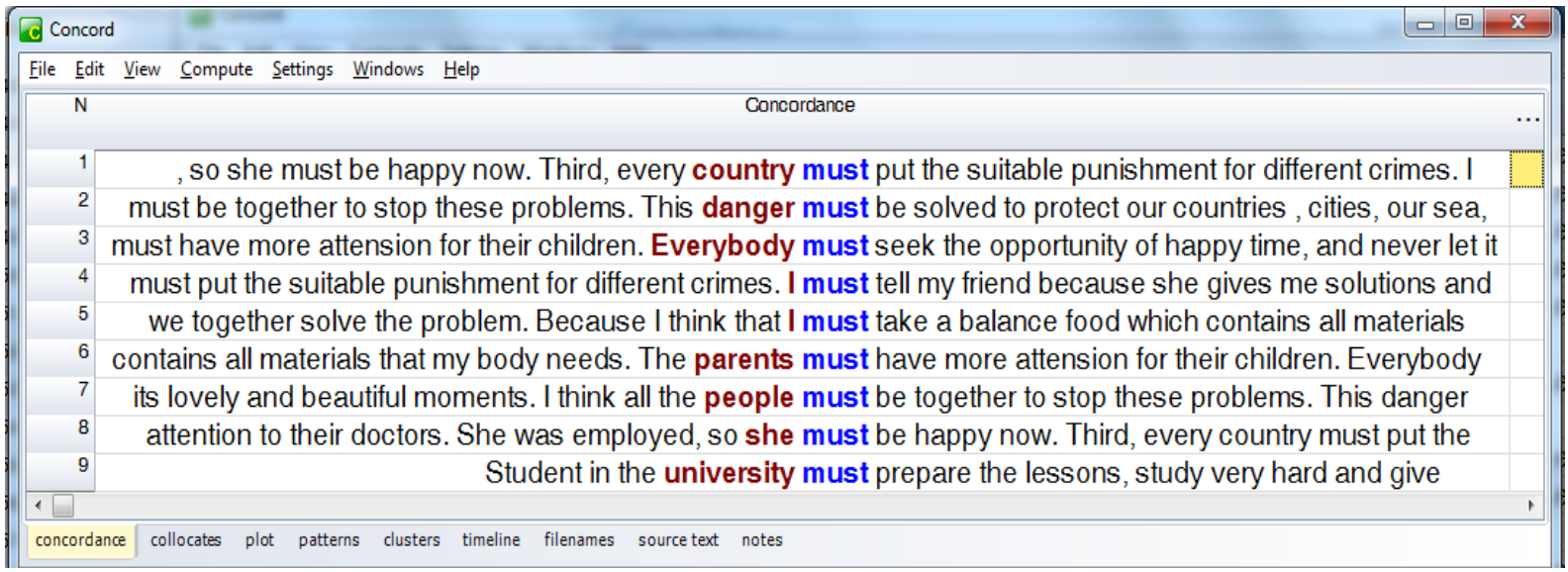

Figure 2. Concordance lines of 'must' in the leaner corpus.

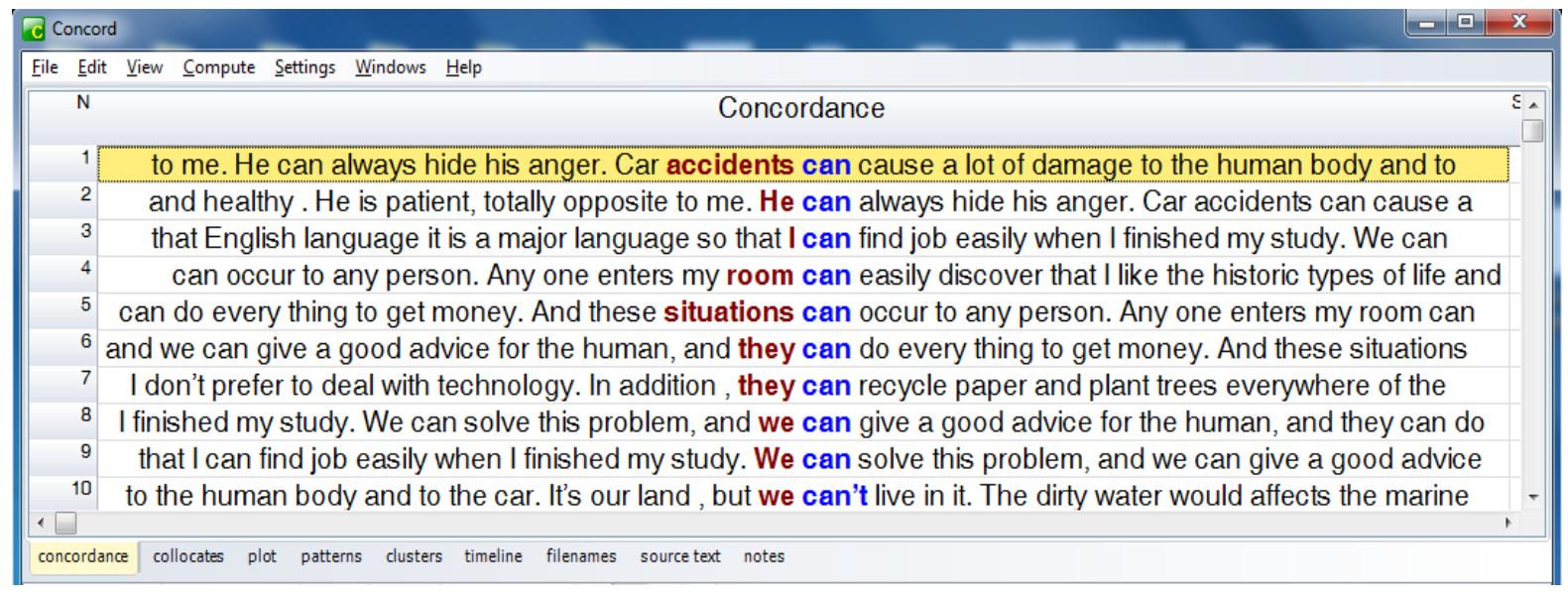

Figure 3. Concordance lines of 'can' in leaner corpus.

Although 'must' is typically used to express necessity, the strength of the modality expressed is not constantly the same. A careful examination of the examples in (5) illustrates this.

(5) a. The ball must touch the ground.

b. He must be sick.

The objective 'must' in (5a) expresses a strict necessity while the subjective 'must' in (5b) expresses a confident inference. Yet, the meaning conveyed by (5b) is definitely much weaker than the one expressed by the unmodalized sentences as in 'He is sick.'

Except for the eighth concordance line, 'must' in all the concordance lines in Figure (2) has deontic readings as it expresses different strengths of obligation. The eighth concordance line, in contrast, expresses an epistemic reading. Accordingly, unlike all other examples shown in Figure (2), which can be paraphrased 'it is necessary...', the eighth concordance line is paraphrased as 'it is certain that ... or the only conclusion is that...'

Another striking diversity between the learner corpus and the native corpus is clearly seen in the number of the modal auxiliary 'can' (394 vs. 281, respectively). 'Can', which is the most frequent modal in the learner corpus, (as shown in Table (2)), expresses a range of meanings, including ability (primarily resulting from power), permission, and (logical) possibility/impossibility.

In spite of the divergent deontic and dynamic modality expressed by 'can', it still remains, sometimes, hard to identify the intended meaning, as shown in (6).

(6) a. It can be rainy the whole week.

b. I can lift it easily.

c. Fatimah can swim in the pool.

d. Sudden change of lanes can lead to serious accidents.

In (6a), the modal 'can' expresses possibility while it is interpreted as indicating ability on the part of the subject in (6b). Unlike (6a) and (6b), (6c) has an ambiguous meaning. Firstly, this sentence means that 'Fatimah has the ability to swim in the pool'. The sentence can be also interpreted deontically to express permission. That is, Fatimah has the permission to swim in the pool. The last example (6d), on the other hand, expresses logical possibility.

Contextually speaking, 'can', as shown in the concordance lines below, expresses varied contextual functions and meanings, ranging from dynamic to epistemic to deontic.

The first concordance line presents an example of deontic modality, where the modal 'can' expresses 
'possibility'. Yet, much of the use of 'can' in the learner corpus is related to dynamic modality, as shown in lines (2), (3), (4), (5), (6), (8), (9) and (10); 'can' in all these examples conveys the subject's ability to perform the action. The seventh concordance line, on the other hand, presents an ambiguous case, as it is difficult to identify exactly whether 'ability' or 'permission' is expressed.

The question that arises here is whether or not the extensive overuse of the core modal 'can' is a general tendency or a peculiarity of the interlanguage of Arab students of English. A closer look at the literature shows that 'can' is generally overused in the performance of L2 learners since this modal expresses different, ambiguous and pragmatic meanings, including ability and possibility (Hyland \& Milton, 1997; Biber et al., 1999; Yang, 2018). Similar findings are also reported in Viana (2006: 83). However, although the overuse of 'can' in the learner corpus could be ascribed to a general tendency on the part of learners, it is also feasible to link it to learners' L1 rhetoric where assertion, confidence and ability rather than possibility are favored.

Unlike 'must' and 'can', the interpretation of 'should' in the concordance lines in Figure (4) is purely deontic. 'Should', which is subject-oriented, is used to express advice or the "desired state of affairs" as referred to by Carter \& McCarthy (2006: 653). Again, the overuse of 'should' could be attributed to learners' L1 culture, which is categorized as a collectivistic-oriented culture (Ajami, 2016; Al Suwaidi, 2008; Ali et al., 1997; among others). Thus, learners here could be said to be holding themselves responsible for others, particularly those who committed wrongdoing or those who have not performed a necessary action. As such, what is viewed imposition or interference in others' affairs in avoidance-based or negatively-oriented cultures (Stewart, 2005) is perceived as intimacy-displaying behavior mirroring in-groupness and social solidarity in positively-oriented cultures such as Arabic. This could explain the overuse of 'should' in the learner corpus, as shown in Table (2). The following concordance lines shed more light on the learners' use of 'should'.

It can be easily noticed, based on the concordance lines, in Figure (4), that 'should' is primarily used to express a mild obligation or duty. The 'mild obligation' conveyed by 'should' can be simply contrasted with the 'absolute obligation' expressed by 'must', as shown in (7).

(7) a. You should follow the regulations.

b. You must follow the regulations.

Unlike (7a), the deontic 'must' in (7b) strictly excludes any non-compliance with the regulations as 'must' expresses 'absolute obligation'. A carful look at the concordance lines in Figure (4) explicitly indicates that lines (1), (2), (4), (5), (6), (7), (8), and (9) have an obligation sense. However, the deontic 'should' in the third concordance line is used to express 'recommendation'. 'Should' in the last concordance line, in contrast, expresses neither a 'mild obligation' nor a 'recommendation'. Rather, it implies failure to commit a possible action as the event did not take place.

Except for 'must', the modals presented in Table (2) can be reclassified into two groups, as shown in Table (3). The first category contains the non-past modals while the other includes only the past time ones.

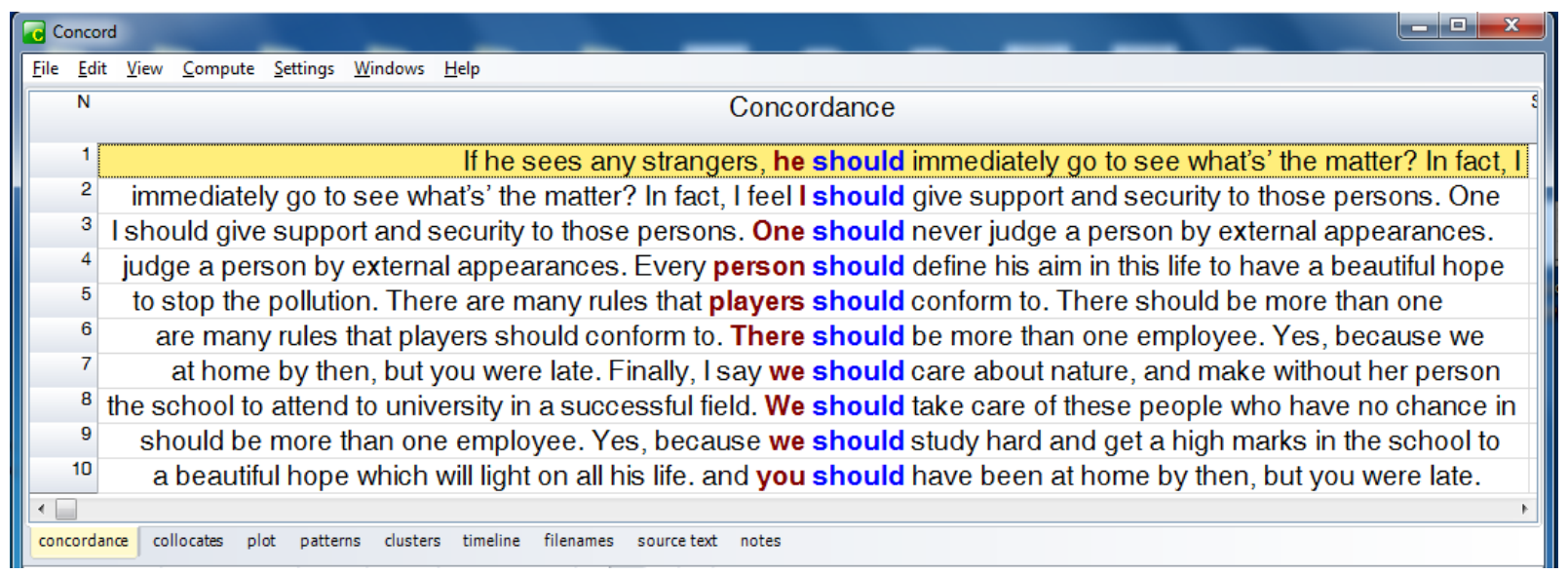

Figure 4. Concordance lines of 'should' in leaner corpus. 
Table 3. Percentage of non-past and past time modals.

\begin{tabular}{|c|c|c|c|c|}
\hline \multicolumn{2}{|c|}{ Non-past time } & \multicolumn{2}{c|}{ Past time } & Total \\
\hline Modal & $\%$ & Modal & $\%$ & \\
\hline May & 87.37 & Might & 12.63 & $100 \%$ \\
\hline Can & 88.14 & Could & 11.86 & $100 \%$ \\
\hline Will & 64.38 & Would & 35.62 & $100 \%$ \\
\hline Shall & 0.99 & Should & 99.01 & $100 \%$ \\
\hline
\end{tabular}

The gap between the two categories is easily observable. Except for 'should', the past-time modals are significantly underutilized. Yet, these findings are a bit consistent with the findings of previous research (Biber et al., 1999; Aijmer, 2002; Viana, 2006, among others).

In addition to the core modal verbs mentioned above, there are two more categories of modals, viz. marginal modals and semi modals. Marginal modals behave like modals in terms of the formation of negative and interrogative forms (without 'do'), zero inflections for number and person, and the bare infinitive complements. Semi-modals, on the other hand, share some common meanings with modals, including permission, obligation, past habits, futurity, and ability.

Table 4. Frequency count of marginal and semi- modals.

\begin{tabular}{|c|c|c|c|}
\hline \multirow{4}{*}{$\begin{array}{c}\text { Marginal } \\
\text { Modals }\end{array}$} & Modal & LC & NC \\
\cline { 2 - 4 } & dare to & 22 & 39 \\
\cline { 2 - 4 } & used to & --- & --- \\
\hline \multirow{4}{*}{ Semi-modals } & (had) better & --- & 18 \\
\cline { 2 - 4 } & have to & 92 & 77 \\
\cline { 2 - 4 } & (have) got to & --- & --- \\
\cline { 2 - 4 } & be supposed to & 1 & 13 \\
\cline { 2 - 4 } & should & 200 & 155 \\
\cline { 2 - 4 } & be going to & 14 & 16 \\
\hline \multirow{4}{*}{ Total } & 348 & 318 \\
\hline
\end{tabular}

Within the two categories, 'have to' and 'should' stand out as the mostly overused modals. Perhaps the overuse of these two modals is easily predicable based on the special meanings conveyed by these modals and learners' L1 rhetoric. Unlike 'must', 'have to' is solely used in the learner corpus to express strong obligation. Though 'have to' is sometimes used to draw conclusions, no occurrence of such usage has been attested in the learner corpus. Therefore, the overuse of 'have to' is similar to the overuse of 'must' as they are both used to express stronger certainty so as to strengthen the force of the expressed proposition.

In addition to the core, marginal and semi-modals, Figure (5) below presents substantial differences between native speakers and learners in the total frequency of the epistemic modality. Epistemic modality markers, as illustrated earlier, refer to linguistic elements, whose primary function is to express the sender's commitment or lack of commitment to the truth of the proposition. Based on the degrees of epistemic commitment, epistemic modals can be categorized into two major categories, viz., boosters and hedges. The disparity between native speakers and learners with regard to the underuse of downtowners or hedges is definitely consistent with both learners' overuse of the core certainty modals (boosters) and the certainty-oriented culture of learners' L1. According to Hyland (1998: 238) hedges help the writer avoid direct responsibility with his or her statement, which in turn helps them maintain personal credibility while at the same time showing adherence to professional honesty and openness.

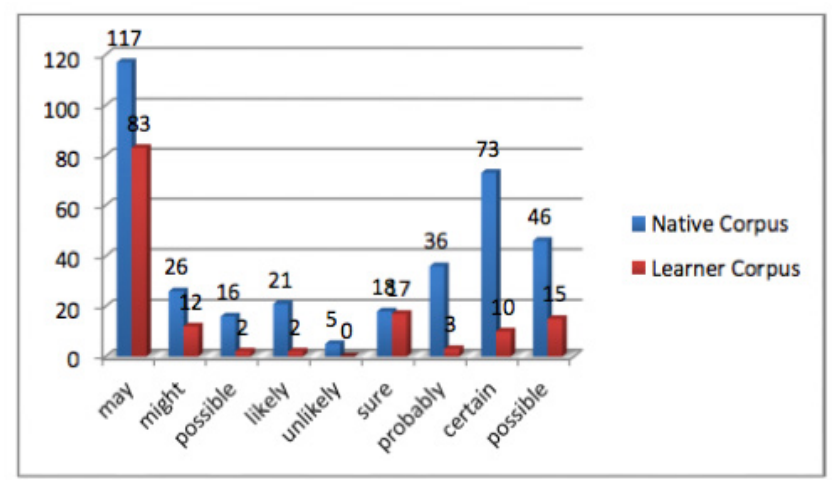

Figure 5. Frequency count of epistemic modality in both corpora.

A look at Figure (5) shows that native speakers tend to extensively use more expressions of probability and possibility than learners do. According to these figures, native speakers have used more than twice as many hedges and downtowners as learners. Btoosh (1999) attributes the use of hedges and downtowners to three pragmatic functions.

1. To express uncertainty and imprecision when the precise information is not available or purposely avoided;

2. To mitigate direct criticism and incitement; \&

3. To avoid sender's commitment to the truth of the proposition.

Yet, it is likely to attribute the disparity between the two corpora in terms of the used hedges and downtowners to two different reasons. First, it is a general tendency on the part of learners to use fewer hedges and downtowners than native speakers (Hinkel, 2003; Hinkel, 2005; Neff-van Aertselaer \& Dafouz-Milne, 2008; Dafouz-Milne, 2008; Btoosh \& Taweel, 2011, among others). Second, Arab EFL learners belong a certainty-oriented culture, where beliefs are considered certainties (Ajami, 2016). Thus, hedges and downtowners are not rhetorically appreciated.

\section{Conclusions}

In this paper, an attempt has been made to account for modality in the performance of Arab EFL learners. To gain a better insight on the very nature of Arab EFL learners' use of modality, the results of the study were compared to a 
similar-sized native writer corpus and were also checked against the findings of some previous relevant studies. Thus, based on the research questions and the comparisons conducted here, this study can be considered an instance of both Contrastive Analysis and Contrastive Interlanguage Analysis. The findings reveal much about the similarities between the results obtained above and the findings of previous relevant studies regarding the overuse and underuse of modal devices. Still, while such similarities are likely to be attributed to some general tendencies, there are several indicators that some of these findings could be ascribed to learners' $\mathrm{L} 1$ rhetoric.

\section{REFERENCES}

[1] Aijmer, Karin. (2002). Modality in advanced Swedish learners' written interlanguage. In Granger, Sylviane; Hung, Joseph; Petch-Tyson, Stephanie (eds.). Computer Learner Corpora, Second Language Acquisition and Foreign Language Teaching. Amsterdam: John Benjamins Publishing Company, 55-76.

[2] Aijmer, Karin \& Bengt Altenberg. (eds.) (1991). English Corpus Linguistics. London: Longman.

[3] Ajami, Hassan (2016). Arabic Language, Culture, and Communication. International Journal of Linguistics and Communication. Vol. 4, No. 1, pp. 120-123.

[4] Ali, A., Taqi, A. \& Krishnan, K. (1997). Individualism, Collectivism, and Decision Styles of Managers in Kuwait, The Journal of Social Psychology, Vol.137 No.5, pp. 629-37.

[5] Al Suwaidi, M. (2008). When an Arab executive says "yes": Identifying different collectivistic values that influence the Arabian decision-making process. Unpublished Masters Thesis, University of Pennsylvania: Philadelphia, PA.

[6] Biber, Douglas, Susan Conrad \& Randi Reppen. (1998). Corpus Linguistics: Investigating Language Structure and Use. Cambridge; New York: Cambridge University Press.

[7] Biber, D., Johansson, S., Leech, G., Conrad, S., \& Finegan, E. (1999). Longman grammar of spoken and written English. London: Longman.

[8] Btoosh, Mousa A. (1999). Hedging in Journalistic Arabic Political Discourse during the Third Gulf War. Unpublished Master Thesis, Yarmouk University, Jordan.

[9] Btoosh, Mousa A. \& Taweel, Abeer Q. (2011). Contrastive Rhetoric: Inflation, verbal voices and polyphonic visibility in learners and native speakers' academic writing. Asian EFL Journal, 13(3), 205-228.

[10] Bybee, Joan \& Suzanne Fleischman (eds.) (1995). Modality in Grammar and Discourse. Amsterdam and Philadelphia: John Benjamins.

[11] Carter, R., \& McCarthy, M. (2006). Cambridge Grammar of English: A Comprehensive Guide. Cambridge England; New York: Cambridge University Press

[12] Dafouz-Milne, E. (2008). The pragmatic role of textual and interpersonal metadiscourse markers in the construction and attainment of persuasion: A cross-linguistic study of newspaper discourse. Journal of Pragmatics. 40/1, 95-113.

[13] Depraetere, I., \& Reed, S. (2006). Mood and modality in English, In B. Aarts \& A. McMahon (Eds.), The Handbook of English Linguistics (pp. 269-90). Oxford: Blackwell Publishing Ltd.

[14] Downing, A. \& Locke, P. (1992). A University Course in English Grammar. Hemel Hempstead: Phonix ELT.

[15] El-Hassan, S. (1990). Expressing Modality in English and Standard Arabic. Journal of King Saudi University. 2 (2), pp. 149-166.

[16] Es-saaydeh, B. Y. A. (1996). Modality in English and standard Arabic: a contrasto error analytic study. MA Thesis, Yarmouk University.

[17] Hinkel, E. (2003). Adverbial markers and tone in L1 and L2 students' writing, Journal of Pragmatics, 35(7), 1049-1068.

[18] Hinkel, E. (2005). Hedging, inflating and persuading in 12 academic writing, Applied Language Learning, 14(2), $29-54$.

[19] Huddleston, Rodney D. (2002). The Cambridge Grammar of the English Language. Cambridge, UK: Cambridge University Press.

[20] Hoye, L. (1997). Adverbs and modality in English. London $\&$ New York: Longman

[21] Hyland, K. \& Milton, J. (1997). Qualification and certainty in L1 and L2 students' writing. Journal of Second Language Writing, 16 (2): 183-205.

[22] Hyland, K. (1998). Persuasion and Context: The Pragmatics of Academic Metadiscourse' Journal of Pragmatics 30: $437-455$.

[23] Kehayov, Petar (2017). The Fate of Mood and Modality in Language Death: Evidence from Minor Finnic. Berlin/Boston: De Gruyter Berlin/Boston.

[24] Kennedy, G. D. (1990). Collocations: Where Grammar and Vocabulary Teaching Meet.In S. Anivan, (Ed.) Language Teaching Methodology for the Nineties (pp. 215-229). RELC, Singapore.

[25] Kennedy, G. (1998). An Introduction to Corpus Linguistics. Longman: London \& New York.

[26] Lorenz, Gunter. (1998). Overstatement in advanced learners' writing: stylistic aspects of adjectives intensification. In Granger, Sylviane (ed.). Learner English on Computer. Longman: London and New York.

[27] Lyons, J. (1977). Semantics. (2 vols) Cambridge: Cambridge University Press.

[28] McEnery, T., \& Wilson, A. (1996). Corpus linguistics. Edinburgh: Edinburgh University Press.

[29] Mitchell, Keith. (2009). Semantic ascent, intersubjectivty and In: Raphael Salkie,Pierre Busuttil,Johanvan der Auwera. Modality in English: Theory and Description. Berlin: Mouton de Gruyter.55-78

[30] Milton, J. \& Hyland, K. (1999). Assertions in students' academic essays: A comparison of L1 and L2 writers. In R. 
Berry, B. Asker, K. Hyland, \& M. Lam (Eds.), Language analysis, description and pedagogy (pp. 147-161). Hong Kong: HKUST.

[31] Mortelmans, Tanja. (2010). Epistemic must and its Cognates in German and Dutch. The Subtle Differences. Unpublished manuscript. Antwerp: University of Antwerp.

[32] Neff-van Aertselaer, J. A., \& Dafouz-Milne, E. (2008). Argumentation patterns in different languages: An analysis of metadiscourse markers in English and Spanish texts. In M. Pütz \& J. A. Neff-van Aertselaer (Eds.), Developing contrastive pragmatics: Interlanguage and cross-cultural perspectives (pp. 87-102). Berlin, Germany: Mouton de Gruyter.

[33] Nuyts, Jan (2006): Modality: Overview and linguistic issues in Frawley, William (ed.) The expression of Modality Berlin-New York: Mouton de Gryuter.

[34] Palmer F. (1990), Modality and the English Modals. London and New York: Longman.

[35] Stefanescu, Andra. (2007). The modal verbs can and may in English and Spanish. Diploma Thesis, University of Bucharest.

[36] Stewart, M. (2005). Politeness in Britain: "It's only a suggestion... ". In: Hickey, L. and Stewart, M. (2005). Politeness in Europe. Clevedon, England, and Buffalo: Multilingual Matters. 116-129

[37] Viana, Viana. (2006). Modals in Brazilian advanced EFL learners' compositions: A corpus-based investigation. Profile Issues in Teachers' Professional Development, 7, pp. 77-86

[38] Yang, Xiaowan. (2018). A Corpus-based Study of Modal Verbs in Chinese Learners' Academic Writing. English Language Teaching; Vol. 11, No. 2, pp. 122-130. 